\title{
O hábito da leitura dos universitários
}

\author{
Maria de Fátima da Silva ${ }^{1}$ \\ Elane Rafaella Cordeiro Nunes ${ }^{2}$ \\ Jaqueline Maria da Silva ${ }^{3}$ \\ Ed Lauriana da Silva ${ }^{4}$ \\ Silvio Serafim de Oliveira ${ }^{5}$
}

\section{Resumo}

O conhecimento pode ser encontrado através da leitura é o meio mais importante para o processo de ensino-aprendizagem. Assim, esse estudo tem como objetivo analisar quais são os hábitos de leituras de universitários do curso de administração da Faculdade de Filosofia, Ciência e Letras de Caruaru, identificando os principais meio de pesquisa utilizados. A pesquisa foi descritiva, bibliográfica e de campo. Entrevistou-se 100 alunos do curso de administração de forma aleatória. Após a coleta dos dados foi utilizada estatística descritiva. Houve predominância do sexo feminino, de pessoas com menos de 25 anos, solteiros, e com receita familiar de 1 a 3 salários mínimos. A maioria dos entrevistados usa a internet como fonte de pesquisa e não apresenta o hábito de ler livros com frequência, no entanto, compram e ler em média 2 livros por ano. Conclui-se que a internet influência nos hábitos e comportamento dos universitários.

Palavra chave: Processo de ensino-aprendizagem; ensino superior; habilidade de leitura

\begin{abstract}
Reading is the most important means for the teaching-learning process. This study aims to analyze the reading habits of students university of Faculdade de Filosofia, Ciências e Letras de Caruaru, identifying the main research methods used. The research was descriptive, bibliographical and field. Surveyed 100 students in random order. After collecting data was used descriptive statistics. Patients were predominantly female, people were under 25 years old, single, and income of 1 to 3 minimum wages. Most respondents use the internet as a source of research and do not have the frequent habit of reading. However, most purchase and read on average two books a year. It concluded that influence of the Internet in habits and behavior of university students.
\end{abstract}

Keyword: teaching-learning process; university; reading ability

\footnotetext{
${ }^{1}$ Especialista em Planejamento Tributário, Universidade Federal de Pernambuco, Pernambuco, Brasil- Email: f4tyma.adm@gmail.com

2 Doutoranda da Universidade Federal Rural de Pernambuco, Pernambuco, Brasil- E-mail: elane.rafaela@hotmail.com

${ }^{3}$ Mestranda especial da Universidade Federal de Pernambuco, Pernambuco, Brasil- E-mail: jacksilva.love@hotmail.com

${ }^{4}$ Bel. Ciências Contábeis, MBA em orçamento e Gestão Financeira, Unifavip-Devery, Pernambuco, Brasil-E-mail: edlaurinha@hotmail.com

5 Especialista em Extensão Rural. Universidade Federal de Alagoas, Alagoas, Brasil- E-mail: silvio.science@gmail.com
} 


\section{Introdução}

Em uma sociedade moderna onde as trocas sociais acontecem por meio da leitura, da escrita, da linguagem oral e visual, entende-se que esses são os elementos capazes de produz a memória cultural de um país, sendo um meio importante para o conhecimento e a transformação das ideias, dos instrumentos e técnicas produzidos pelo homem. Neste contexto Freire (2006) defende que a leitura deve ser vista como uma conquista do ser humano em seu processo de evolução. Onde o reflexo da realidade histórica do povo brasileiro se projeta na educação, desde a estrutura familiar, passando pelo Ensino Fundamental e estendendo-se até o Ensino Superior.

Na educação superior é comum deparar-se com alunos com formação deficitária que chegam à universidade com conhecimentos gerais e linguísticos limitados (VIAN, 2006). Tourinho (2011, p.326) afirmar que o estudante de nível universitário no país, em sua maioria, despreza a leitura como fonte de entretenimento, informação e crescimento pessoal, limitando-se, na maior parte das ocasiões, a apenas ler aquilo que é obrigado por necessidade das disciplinas cursadas, como atividades, apostilas e livros passados pelos professores.

De acordo com Cunha e Santos (2007) alguns dos desafios atualmente enfrentados pelas universidades é que seus alunos se tornem bons leitores e, para isso, é preciso que todos os responsáveis pelo ensino estejam convencidos que a leitura é de extrema importância para a vida do indivíduo, tanto social como cultural (OLIVEIRA, 2011). No entendimento dos autores Amorim e Farago (2015) a falta do hábito de leitura pode acarretar problemas de compreensão de leitura entre os estudantes, problemas os quais se projetam na vida acadêmica e no futuro profissional. Quanto menor a compreensão em leitura, maior os erros nas produções escrita, o que torna o desempenho dos universitários bem distantes do que seria desejado nessa etapa de escolarização (VIAN, 2006).

Segundo Souza (2007) o conhecimento pode ser encontrado através da leitura, possibilitando a formação de uma sociedade consciente de seus direitos e de seus deveres, possibilita que estes tenham uma visão melhor de mundo e de si mesmos. A escrita está presente em toda sociedade, em todo lugar e com uma grande diversidade de textos que necessitam da leitura para sua interpretação, compreensão dos diversos tipos de textos com diferentes gêneros textuais contribuindo para a autonomia dos cidadãos (OLIVEIRA, KOYAMA, SILVA, 2011). 
Conforme Souza (2007), não basta apenas ler, é importante analisar, interpretar, conhecer para agregar valor à atividade ou necessidade que se tem. Na seleção de determinado livro, revista ou jornal, existe uma intenção para justificar a escolha. É fundamental a interação dos elementos textuais com os conhecimentos do leitor (COLOMER, CAMPS, 2002). Os mesmos ponderam que o processo da leitura é realizado por meio de teorias que deixam explícito como os indivíduos interpretam e processam as informações, tendo o uso dos processos mentais e os processamentos informáticos.

Ou seja, a leitura é fonte de conhecimento e informação (ZAGO, 2006), que possibilita a formação de ideias e o aprimoramento das habilidades (OLIVEIRA; KOYAMA, SILVA, 2011). E por tal motivo é o meio mais importante para o processo de ensino-aprendizagem, pois isso possibilita a construção de habilidades linguísticas para compreender e interpretar os textos, ensinando o aluno a falar e escrever melhor. É por meio da expressão e compreensão que o indivíduo transmite todas as experiências vivenciadas seja por opinar, argumentar ou manifestar algo (BAMBERGER, 1995).

Neste contexto, considerando essas informações sobre importância da leitura e escrita no meio acadêmico e profissional, buscou-se analisar quais são os hábitos de leituras de universitários do curso de administração da Faculdade de Filosofia, Ciência e Letras de Caruaru, identificando os principais meios de pesquisa utilizados.

\section{Referencia teórico}

\section{A leitura no contexto social}

No Brasil um dos fatores que interferem no desempenho de aprendizagem da leitura é de ordem econômico-social. Tourinho (2011, p. 327) afirma que "as relações do homem com o mundo estão mediadas por sua percepção e construídas pela linguagem. Esta é de caráter social, pois a condição de sua existência é a troca e a comunicação". Ou seja, o indivíduo precisa da leitura para seu convivo social, e esta assume o papel determinante para uma boa convivência tanto no ambiente de trabalha como no contexto individual.

Para Orlandi (1998, p. 220) “a leitura não é uma questão de tudo ou nada, é uma questão de natureza, de modos de relação, de trabalho e de produção de sentido" onde o ato de ler implica em participar do processo coletivo de construção dos sentidos, em um contexto social e cultural. Filipouski (1982, p. 108) afirma que a escola é o lugar ideal 
para a promoção do hábito de ler nas crianças e jovens, devendo então se preocupar em desenvolver estratégias para o ensino eficaz da leitura, desenvolvendo nas crianças o prazer da leitura muito antes de aprender a ler o que resultará em um adulto apaixonado pela leitura. No entanto, a escola, em especial pública, em sua maioria das vezes não está preparada para desenvolver eficazmente o processo de leitura, por ser uma instituição deficitária de recursos, porém, é ainda o espaço que muito brasileiros disponibiliza em favor da sua própria leitura.

Segundo Silva (2005, p.32) "seria difícil conceber uma escola onde a ato de ler não estivesse presente, isto ocorre porque o patrimônio histórico, cultural e científico da humanidade se encontra fixado em diferentes tipos de livros".

Para Freire (2006, p. 11), "o ato de ler não se esgota na decodificação pura da palavra escrita ou da linguagem escrita, mas se antecipa e se alonga na inteligência do mundo". Lajolo e Zilberman (2002) afirmam que cada leitor entrelaça o significado pessoal de suas leituras de mundo com os vários significados que ele encontrou ao longo da história de um livro, por exemplo. O ato de ler, então, não deve representar apenas a decodificação, já que esta não se liga imediatamente a uma experiência, fantasia ou necessidade do indivíduo. De acordo com os Parâmetros Curriculares Nacionais - PCN (1997, p. 54):

Um leitor competente é alguém que, por iniciativa própria, é capaz de selecionar, dentre os trechos que circulam socialmente, aqueles que podem atender a uma necessidade sua. Que consegue utilizar estratégias de leitura adequada para abordá-los de forma a atender a essa necessidade.

Segundo Zilberman (1988, p. 56):

O processo de formação do leitor está vinculado num primeiro momento à característica físicas (dimensões materiais) e sociais (interação humana) do contexto familiar, isto é, presença de livros, de leitores e situações de leitura que configura um quadro específico de estímulo sócio cultural.

Neste entendimento a habilidade da leitura e escrita não podem ser tomadas de forma separada da informação cultural que cada indivíduo possui como também o senso crítico de escolha de construção de conhecimento, neste contexto Hirsch Jr. (1988) afirma que o analfabetismo não é simplesmente, incapacidade de ler e escrever, mas 
uma deficiência de informação cultural, que não pode ser remediada com métodos centrados exclusivamente na técnica ou no treinamento de habilidades.

Para Pugh e Pawan (1991) as dificuldades de leitura estão relacionadas a deficiências em capacidades cognitivas básicas, como a habilidade de compreender variáveis, fazer proposições, identificar lacunas de informação, distinguir entre observações e inferências, raciocinar hipoteticamente e exercitar a meta cognição. Assim a falta do hábito da leitura pode estar relacionada às dificuldades entre ler e compreender o que estar lendo.

\section{A importância da leitura no ensino superior}

A leitura é um importante instrumento para a vida social e cognitiva do sujeito, o que qualifica sua inserção no âmbito social, político, econômico e cultural (BOSO, 2010, p. 24). A leitura do texto escrito, segundo Kleiman $(2008$, p.10) "é um ato social entre dois sujeitos, leitor e autor, que interagem entre si obedecendo a objetivos e necessidades socialmente determinados." De modo a buscar satisfazer os objetivos que guiam a leitura.

Witter (1999) afirma que embora a leitura esteja presente nas atividades dos universitários, as instituição de ensino superior não prioriza a leitura acadêmica de cunho científico como parte integrante do conhecimento. Pires (2012, p.368) afirma que deveria haver no ensino superior o hábito da leitura, devido ao seu alto grau de exigência e complexidade quanto na realização de trabalho de natureza acadêmica como: artigos, resumos, relatórios e monografias.

No entendimento de Witter (1999) o indivíduo, ao chegar à universidade, já deveria possuir uma capacidade de se adaptar aos diferentes conteúdos, possuindo também um bom desempenho em leitura. Santos (1998) afirma que muitos entram na universidade sem compreender sequer um texto, ou seja, não conseguem interagir com o texto, e não são capazes de compreender significativamente o conteúdo que leram neste contexto Alves (2007, p. 08) afirma que os universitários "não conseguem buscar e selecionar as informações do texto; não apresentam uma atitude crítica e criativa em relação ao texto lido; a maioria não gosta de ler, sejam livros da própria área que estuda, seja outro tipo de leituras".

Moro et al (2002, p.4) conceituam o "ser" leitor como aquele que entende e amplia a compreensão do mundo e está em permanente relação consigo mesmo. 
Acredita-se qie que os universitários que tem o hábito de ler, obtêm um bom desempenho em diversas disciplinas por conseguir extrair dos textos as informações necessárias para sua compreensão e interpretação, com mais facilidade.

Para Carvalho et. al. (2006, p. 20) uma leitura eficiente na sociedade do conhecimento prevê que: "o ser humano precisa realizar leituras diversificadas e de qualidade para sobreviver na era da globalização. Portanto o mais importante é saber selecionar as leituras evitando a sobrecarga informacional". Santos (2008) considera a leitura relevante no contexto da prática social como ação transformadora, por contribuir para o desenvolvimento do homem, e, consequentemente, da sociedade.

\section{Metodologia}

Essa pesquisa foi descritiva por descrever a teoria e os resultados encontrados a fim de esclarecer a importância do tema em estudo. Segundo Dias, Molina e Santos (2007, p.126) esse tipo de pesquisa é utilizado quando o pesquisador tem o intuito de descrever e caracterizar algum fenômeno, por exemplo, as características de um grupo específico.

Em se tratando de meios, essa pesquisa foi bibliográfica e de campo. Uma vez que foram citadas opiniões de vários autores procurando comparar os estudos já existentes com o resultado do questionário, identificando a presença ou ausência do hábito de leituras e sua principal fonte de pesquisa pelos universitários. E que a pesquisa bibliográfica é caracterizada pelo uso de materiais, como livros, revistas, artigos, além de pesquisas em sites especializados (MICHEL, 2009).

Segundo Roesch (2007) o delineamento da pesquisa, além de outros aspectos, consiste em tornar o problema pesquisável, bem como determina quem vai ser pesquisado e quais questões serão levantadas. Os itens que se seguem esclarecem melhor esses detalhes. Segundo Vergara (2010, p. 476) a população amostral ou amostra “[...] é uma parte do universo (população) escolhida segundo algum critério de representatividade".

Portanto a instituição em estudo é um complexo educacional que compreende um campus universitário com mais de meio século, formando profissionais de diferentes áreas, no Agreste de Pernambuco, conta com 11 cursos de nível superior com cerca de 3.000 alunos, deste universo foi selecionado 100 alunos do curso de administração de forma aleatória.

Revista Leitura V.2 no 56 - jul/dez 2015 - Número regular - Autor/a: Silva et alli - p. 60 - 73. 
A pesquisa ocorreu em duas etapas distintas, na primeira foi realizado um levantamento da teoria no qual resultou na elaboração do questionário para investigar em campo o hábito da leitura dos universitários do curso de Administração da Faculdade de Filosofia, Ciência e Letra de Caruaru - FAFICA. E na segunda etapa foi à análise dos dados obtidos através do questionário aplicado.

Segundo MATTAR (2008) o questionário é um instrumento de observações baseadas em uma sequência de questões escritas e que são dirigidas ao um grupo de pessoas, para constatar suas opiniões a respeito de um determinado assunto levando em considerações aspectos demográficos. Para Ketele (1999 p. 18) a entrevista é um método de escolha de informações que consiste em conversas orais, individuais ou de grupos, com várias pessoas selecionadas cuidadosamente, cujo grau de pertinência, veracidade e viabilidade é analisado na perspectiva dos objetivos da escolha de informações.

O estudo buscou entender diversos fatores incluídos no comportamento dos universitários que estão relacionados com o hábito da leitura e perspectiva de investir no capital intelectual. Após os contatos iniciais com os universitários escolhidos aleatórios, foi efetuada a coleta dos dados através de questionários individuais com 11 perguntas fechadas, nos meses de outubro e novembro de 2014 que permitiram uma melhor exploração das características dos entrevistados.

Após a coleta dos dados foi utilizada estatística descritiva com o emprego da distribuição de frequência absoluta e relativas. Para uma melhor compreensão dos resultados obtidos, os dados foram apresentados em quadro e gráficos.

\section{Resultados e discussão}

Os perfis dos participantes do universo amostral estão representados através de número seguido de percentagem que estão citados na Tab.1. Em termos de gênero houve predominância do sexo feminino (57\%), os homens representaram 43\%. Com relação à faixa etária, 56\% têm menos de 25 anos, $30 \%$ têm de 26 a 30 anos, $8 \%$ tem de 31 a 35anos, $4 \%$ tem de 36 a 40 anos e $2 \%$ têm de 41 a 50 anos. Quanto ao estado civil, $52 \%$ são solteiros, $40 \%$ casados, e $8 \%$ divorciados. Em relação à receita familiar $50 \%$ têm de 1 a 3 salários mínimos, 38\% tem 4 a 6 salários mínimos e $12 \%$ tem mais de 6 salários mínimos. 


\begin{tabular}{lcc}
\hline Variáveis & $\begin{array}{c}\text { Frequência } \\
\text { absoluta }\end{array}$ & $\begin{array}{c}\text { Frequência } \\
\text { Relativa \% }\end{array}$ \\
\hline Gênero & 43 & 43 \\
Masc. & 57 & 57 \\
Femin. & 56 & 56 \\
Faixa Etária & 30 & 30 \\
< 25 Anos & 8 & 8 \\
26 a 30 Anos & 4 & 4 \\
31 a 35 Anos & 2 & 2 \\
36 a 40 Anos & & \\
41 a 50 Anos & 52 & 52 \\
Estado Civil & 40 & 40 \\
Solteiro (a) & 8 & 8 \\
Casado (a) & & \\
Divorciado (a) & 50 & 50 \\
Receita familiar & 38 & 38 \\
De 1 a 3 salários min & 12 & 12 \\
De 4 a 6 salários min & & \\
Mais de 6 salários min & & \\
\hline
\end{tabular}

Tabela 1 - Perfil da Amostra.

Fonte Autoria própria 2014.

Em relação à identificação com o curso de administração, $89 \%$ afirmaram que se identificam com o curso de administração e $11 \%$ acredita não se identifica. Vale ressaltar que essa variável é um importante fator para permanência ou desistência do curso. Segundo Franco e Feitosa (2006) quando o aluno se identifica com a área que está estudando há um estimulo para os alunos procurarem o conhecimento e direcionálo para um propósito, de forma proativa. Sugere-se que os universitários em análise ao se identificarem com o curso estão satisfeito com a escolha do curso e tem maior probabilidade de maior desenvoltura na vida acadêmica e profissional.

A maioria dos universitários $(81 \%)$ ocupam de forma paralela vagas no mercado de trabalho, principalmente no setor de vendas, que emprega $29 \%$ dos entrevistados. O setor financeiro concentra $18 \%$, logística $15 \%$, recursos humanos $13 \%$ e contabilidade $6 \%$ dos entrevistados, conforme pode ser visualizado no Graf. 1. Este fato demonstra a importância da oferta de curso superior no período noturno, por facilitar o ingresso das pessoas que trabalham nos centros universitários. 


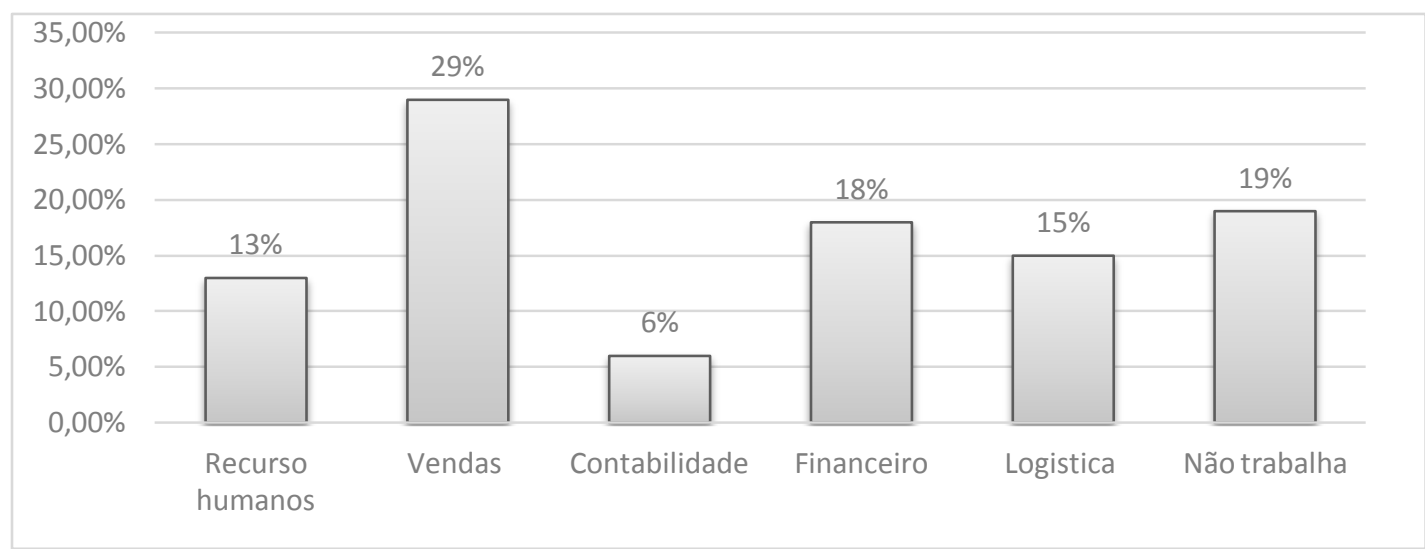

Gráfico 1. Se trabalha qual sua área de atuação profissional Fonte: Elaboração própria, 2014

Como propõe Yin (2005), enquanto pesquisadores, os alunos são responsáveis pela busca de informações e pelo meio de coleta destas informações. Assim, os alunos são responsáveis por estabelecer sua própria base de conhecimento.

Analisando a principal fonte de pesquisa utilizada para execução da leitura observou-se que a internet representou $43 \%$, os livros $27 \%$, revista $12 \%$ e $9 \%$ em documentários e jornal. A diversidade de fontes de leitura por parte tem relevante importância, pois no processo de formação do ensino-aprendizagem a interação dos elementos textuais em diferentes fontes permite uma maior transformação de dados em conhecimento. Quando se determina qual a fonte a ser pesquisa existe uma intenção para justificar a escolha. E após a escolha não basta apenas ler, é importante analisar, interpretar, conhecer para agregar valor à atividade ou necessidade que se tem (SOUZA, 2007). Outro fato interessante é a predominância do uso da internet confirmado a expansão da inclusão digital no contexto social brasileiro dos centros universitários.

Quando se avaliou a frequência da leitura nessas fontes de pesquisas, observouse que a internet também é a principal fonte (52\%). O que permite afirmar que há um uso constante da internet pelos universitários, e que esta fonte esta inserida no cotidiano dos mesmos. Acredita-se que internet ocasionou grandes mudanças culturais, vinculadas "à emergência de novas maneiras dominantes pelas quais experimentamos o tempo e o espaço" (HARVEY, 1992, p.8).

Ao analisar a quantidade de livros comprados ou lidos nos últimos 12 meses, observou-se que $25 \%$ compraram e leram 2 livros, $21 \%$ não compraram e não leram nenhum livro, $20 \%$ leram 1 livro, 18\% leram e compraram 3 livros, $10 \%$ leram e compraram 6 livros e $6 \%$ comprou e leram 8 livros. 
Realizar um diagnóstico entre obtenção e leitura de um livro torna-se importante pelo fato que o leitor competente é alguém capaz de selecionar por iniciativa própria dentre os trechos que circulam socialmente, aqueles que podem atender a uma necessidade sua. Que consegue utilizar estratégias de leitura adequada para abordá-los de forma a atender essa necessidade (BRASIL, 1998a, v. 2, p. 54). Escolher um livro e executar sua leitura desperta o interesse pelo significado das palavras, resultando no desejo de aprender a ler e a escrever, tendo como foco a construção de seu conhecimento, desenvolvendo desta forma narrativa e diálogo eficiente (PORCA, CHIA, BARONE, 2011).

Analisando o hábito de leitura dos entrevistados, $51 \%$ não o praticam com frequência, $36 \%$ costuma ler todos os dias e $13 \%$ afirma nunca ler. O que se pode concluir que os universitários necessitam aumentar o hábito da leitura. $\mathrm{O}$ inicio e execução dessa atitude de forma rotineira irá possibilitar uma construção de habilidades linguísticas para compreender e interpretar os textos, ensinando o aluno a falar e escrever melhor (AMORIM, FARAGO, 2015). E desta forma, conseguir ter melhor expressão e compreensão no meio de vida pessoal, acadêmico e profissional, por ter maior base para opinar, argumentar ou manifestar seus conhecimentos.

\section{Considerações Finais}

Ler é muito mais do que interpretar as letras para compreender a mensagem, visto que inclui o sentimento e a atribuição de significado ao texto, além do relacionamento do conteúdo com outros conhecimentos já adquiridos. A leitura é considerada um meio de proporcionar reflexões e questionamentos, haja vista que está presente no dia-a-dia do indivíduo, por isso é importante no meio acadêmico ter o hábito da leitura para obtenção de um ciclo de formação eficiente.

Neste contexto, o trabalho buscou analisar quais são os hábitos de leituras de universitários do curso de administração da Faculdade de Filosofia, Ciência e Letras de Caruaru, identificando os principais meio de pesquisa utilizados. Através de uma pesquisa de campo que foi retirada através de questionário respondido por 100 alunos do primeiro ao oitavo período do curso.

Verificou-se que a maioria dos universitários do curso de administração utiliza a internet como principal fonte de pesquisa para execução da leitura, não apresenta o 
hábito de ler livros com frequência, no entanto, compram e ler em média 2 livros por ano.

Com esses dados pode-se perceber que a internet influência nos hábitos e comportamento dos universitários. Acredita-se que essa influencia esta relacionada com a inserção desses indivíduos na geração que nasceram em meio às mídias digitais já que a idade da maioria dos entrevistados tem menos de 25 anos, demonstrando a ampliação da inclusão digital em todas as classes sociais. Vale ressaltar, que independente de ser universitário faz necessário que o indivíduo pratique o hábito da leitura, uma vez que conhecimento é a porta para o desenvolvimento intelectual e sucesso profissional. Cabe registrar que a inserção de outros indivíduos poderia apresentar resultados mais expressivos, mas isso fugiria ao escopo desse trabalho.

\section{Referências}

ALVES, A. L. M. S. Leitura e Universidade: comportamento de leitura na formação do pedagogo da UFPA. In: simpósio brasileiro/v congresso luso brasileiro colóquio ibero-americano, 23. Porto Alegre. Por uma Escola de Qualidade para Todos. Anais... Porto Alegre: UFRGS/FEFED/PPGEDU, 2007. V. 1. p. 1-15.

AMORIM, M. C. B; FARAGO, A. C. As práticas de leitura na educação infantil, Cadernos de Educação Ensino e Sociedade, Bebedouro - SP, 2 (1): 134-154, 2015.

BAMBERGER, R. Como incentivar o hábito da leitura. 7. ed. Ática. São Paulo, 2002.

BOSO, A. C; Aspectos cognitivos da leitura: conhecimento prévio e teoria dos esquemas. Revista ACB: Biblioteconomia em Santa Catarina, Florianópolis, v. 15, n. 2, p. 24-39, jul./dez. 2010. Disponível em: < http://revista.acbsc.org.br/index. php/racb/article/view/716/pdf_39>. Acesso em: 14 fev. 2016.

CARVALHO, L. da S.; A Leitura na sociedade do conhecimento. Revista ACB: Biblioteconomia em Santa Catarina, Florianópolis, v. 11, n. 1, p. 19-27, jan./jul. 2006. Disponível em: < http://revista.acbsc.org.br/index. php/racb/article/view/459/576>. Acesso em: 14 fev. 2016.

COLOMER, T.; CAMPS, A. Ensinar a ler, ensinar a compreender. São Paulo: Artmed, 2002.

CUNHA N. B.; SANTOS A. A. A.; Relação entre a compreensão da leitura e a produção escrita em universitários. Revista Psicologia Reflexão Critica. Porto Alegre, z2006, v. 19, n. 2 [citado em 2007 mai. 25] p. 237-245. Disponível em: <http://www.scielo.br/pdf/prc/v19n2/a09v19n2.pdf> acesso em 16 out. 2014. 
DIAS, V.F.; MOLINA, N.L; SANTOS, G do R. C.M.; Orientações e dicas práticas. Disponível em: <http://www.agenciabrasil.gov.br/noticias/2007/07/09/materia. 2007Educação e Emancipação, São Luís, v. 1, n.1, jan./fev. 2002.

FEITOSA, M.G.G.; FRANCO, A.P.; Da sala de aula de aula ao mundo empresarial: Compreendendo a aprendizagem dos consultores juniores em suas relações com o sistema cliente. In: encontro nacional da associação nacional da pós-graduação em administração-ENANPAD, XXX, 2006, Salvador-BA. ANPAD, 2006.

FILIPOUSKI, A. M. R. Atividades com textos em sala de aula. In: ZILBERMAN, Regina (Org.) Leitura em crise na escola: as alternativas do professor. Porto Alegre: Mercado Aberto, 1982. p. 107-132. (Série Perspectivas, 1).

FREIRE, P. Pedagogia da autonomia. 7. ed. São Paulo: Paz e Terra, 2006.

HARVEY, D. Condição pós-moderna. São Paulo: Loyola, 1992.

HIRSCH Jr., E. D. (1988). Cultural Literacy. New York: Vintage Books (Random House).

TOURINHO C. refletindo sobre a dificuldade de leitura em alunos do ensino superior: "deficiência" ou simples falta de hábito? Revista Lugares de Educação, Bananeiras/PB, v. 1, n. 2, p. 325-346, jul. Dez. 2011 ISSN 2237-1451 Disponível em http://periodicos.ufpb.br/ojs2/index.php/rle acesso em 29 de fev. 2016.

KETELE, J. M. de. Metodologia da recolha de dados: fundamentos dos métodos de observação, de questionários, de entrevistas e de estudo de documentos. Lisboa: Instituto Piaget, 1999.

KLEIMAN, A. Texto e Leitor: Aspectos cognitivos da Leitura, Campinas: Pontes, 2008.

LAJOLO, M.; ZILBERMAN, R. Do mundo da leitura para a leitura do mundo. 6.

MATTAR, F. N. Pesquisa de marketing. 3. ed. São Paulo: Atlas, 2001.

MICHEL, M. H. Metodologia e pesquisa científica em ciências sociais. 2. ed. São Paulo: Atlas 2009.

MONTEIRO, F. A. As Ações culturais como incentivo à leitura na Biblioteca Pública de Barcarena-Pa. 2010. Belém. 57 f. Trabalho de Conclusão de Curso (Graduação) - Faculdade de Biblioteconomia, Instituto de Ciências Sociais Aplicas, Universidade Federal do Pará, Belém, 2010.

MORO, E. L. S.; SOUTO, G. P.; ESTABEL, L. B. A Influência da Internet nos Hábitos de Leitura do Adolescente. In: III Seminário de Educação e de Comunicação, 2002, Pelotas/ RS. III Seminário de Educação e de Comunicação - Anais. Pelotas/RS: UFPEL, 2002. v. 3. Disponível http://www.eci.ufmg.br/gebe/downloads/313.pdf Acesso: 02 fev. 2016. 
OLIVEIRA, C. R. de; KOYAMA, C. M.; SILVA, D. C.; despertar do interesse pela leitura e pela escrita, nos estudantes do curso de ciências contábeis da universidade estadual de londrina, no discorrer da graduação. Revista de estudos contábeis, Londrina, V. 2, N. 2, P.57-71, JAN./JUN. 2011.

OLIVEIRA, K. Universitários dedicam pouco tempo à leitura e aos estudos, revela. ENADE. Agência Brasil, São Paulo: Empresa Brasil de Comunicação, 9 jul. 2007. Disponível em: <http://www.agenciabrasil.gov.br/noticias/2007/07/09/materia. 200707-09.4440958479/view>. Acesso em: 02 fev. 2016.

ORLANDI, E. P. A leitura e os leitores. Campinas-SP: Pontes, 1998.

PIRES, E. A. de N., a importância do hábito da leitura na universidade. Revista ACB: biblioteconomia em Santa Catarina, Florianópolis, v.17, n.2, p.365-381, jul./dez., 2012.

PORCACCHIA, Sonia Saj; BARONE, Leda Maria Codeço. Construindo leitores: uma experiência de oficina de leitura. Estud. psicol, Campinas, v. 28, n.3, 2011. Disponível em: <http://www.scielo.br/scielo. phpscript=sci_abstract\&pid=S0103166X2011 000300012\&lng=pt\&nrm=iso\&tlng=pt>. Acesso em: 16 dez. 2014.

PUGH, S. L. PAWAN, F. (1991). Reading, Writing, And Academic Literacy. R. F. Flippo E D. \& Caverly, C. (Eds.), College Reading And Strategy Programs, Newark: Ira.

ROESCH, Sylvia Maria Azevedo. Projetos de estágio e de pesquisa em administração. $3^{\circ}$ ed. São Paulo: Atlas, 2007.

SANTOS, A. A. A. Leitura entre Universitários: diagnóstico e Remediação. 1998. Tese (Doutorado em Psicologia) - Instituto de Psicologia, Universidade de São Paulo, São Paulo.

SOUZA, Leila. A importância da leitura para a formação de uma sociedade consciente. In: VII Encontro Nacional de Ensino e Pesquisa da Informação. 2007. Disponível em: Acesso em: 22 mar. 2015.

TOURINHO Cleber. Refletindo sobre a dificuldade de leitura em alunos do ensino superior: "deficiência" ou simples falta de hábito? Revista Lugares de Educação, Bananeiras/PB, v. 1, n. 2, p. 325-346, jul. Dez. 2011 ISSN 2237-1451 Disponível em http://periodicos.ufpb.br/ojs/index.php/rle/article/view/10966. Acesso em 02 fev. 2016.

VERGARA Sylvia. Projetos e relatórios de pesquisa em administração. São Paulo: Atlas, 2010.

VIAN Jr O. Gêneros discursivos e conhecimento sobre gêneros no planejamento de um curso de português instrumental para ciências contábeis. Rev. Linguagem em Discurso. 2006; v. 6, n. especial.

WITTER, G. (Org.). Leitura e universidade. Campinas-SP, Alínea, 1999. 
YIN, Robert. Estudo de Caso: Planejamento e Métodos. Ed.4 Porto Alegre, Bookman 2010.

ZAGO, N. Do acesso à permanência no ensino superior: percursos de estudantes universitários de camadas populares. Revista Brasileira de Educação, v. 11 n. 32 maio/ago. 2006. 